Article

\title{
Streaming Electrification of Nycodiel 1255 Synthetic Ester and Trafo EN Mineral Oil Mixtures by Using Rotating Disc Method
}

\author{
Maciej Zdanowski \\ Faculty of Electrical Engineering, Automatic Control and Informatics, Opole University of Technology, \\ Prószkowska 76, 45-758 Opole, Poland; m.zdanowski@po.edu.pl
}

Received: 19 October 2020; Accepted: 21 November 2020; Published: 24 November 2020

\begin{abstract}
Power transformers are the main element of an electric power system. The service life of these devices depends to a large extent on the technical condition of their insulation system. Replacing mineral oils with natural or synthetic ester (retrofilling process) may increase the efficiency and operational safety of transformers, and also limit their adverse environmental impact. It is technically unfeasible to completely remove mineral oil from a transformer. Its small residues form a mixture with fluid ester, with different physicochemical and electric properties. Streaming electrification is one of the phenomena which, under unfavorable conditions, may damage the insulation system of a forced oil cooled transformer. It is necessary to run prophylactic tests for the ECT (electrostatic charging tendency) of insulating liquid mixtures from the point of view of transformer retrofilling, which is being used more often than before. The article presents the results of studies on selected physicochemical, and electrical properties, and the ECT of mixtures of fresh and aged Trafo EN mineral oil with Nycodiel 1255 synthetic ester. In this regard, the density, the kinematic viscosity, the conductivity, and the relative dielectric constant were measured. The molecular diffusion coefficient was determined using Adamczewski's empirical dependency. The streaming electrification was tested in a rotating disc system. The impact of the rotation time, the diameter, and the disc's rotation speed on the amount of the electrification current generated were analyzed. In addition, the co-relation between the electrification current and the composition of the mixture was determined using fresh and aged mineral oil. On the basis of the electrification model, the volume density of the $q_{w}$ charge was calculated, which is a parameter defining the ECT of insulating liquids. Based on the results, it was concluded that the synthetic ester is characterized by a higher susceptibility to electrification than the mineral oil. However, combining synthetic ester with a small amount (up to $20 \%$ ) of fresh or aged mineral oil significantly reduces its ECT, which is beneficial from the point of view of retrofilling power transformers.
\end{abstract}

Keywords: mineral oil; natural ester; synthetic ester; insulation liquid mixtures; power transformers; retrofilling; streaming electrification; ECT; rotating disc system

\section{Introduction}

\subsection{Research of Insulating Liquids Mixtures}

Power transformers are a key element of the equipment in power plants, transmission systems, electro-power companies, and large industrial plants. Replacing or repairing these devices as a result of breakdowns involves large financial expenditures [1,2]. A transformer's long and reliable operation strictly depends on the technical condition of its insulation system [3-6]. For economic reasons, the vast majority of transformers is filled with mineral oils with well-known properties [7-9]. 
Due to tighter fire safety and environmental protection regulations, more often than before the power industry is interested in alternative electro-insulating fluids, which include natural, and synthetic esters [10-13]. Liquid esters are used to fill new or modernized transformers. The process of removing mineral oils from transformers to replace them with liquid esters is defined as retrofilling [14-17]. For technical reasons, it is not possible to completely remove mineral oil from the inside of a transformer. Its small amount (4-7\%) usually remains in the paper insulation, the windings, the core, and in places hard to reach in a transformer [18]. Replacing mineral oil with liquid ester creates in a transformer a mixture with properties different than each base fluid. It is necessary to test the properties of insulating liquids generated as a result of retrofilling to ensure long, effective, and safe operation of power transformers. In this regard, the physicochemical and electrical properties, ageing processes, the flammability parameters and the thermal properties of insulating liquid mixtures were examined. Fofana at al. $[19,20]$ presented the research results of two insulating liquids mixtures, proposed as alternatives to mineral oil. The first part of the investigation presented a comparison of the mixed liquids properties with those of pure liquids. The second part of the studies, evaluates the compatibility of the mixed liquids with insulating papers used in power transformers. Perrier et al. [21] showed the test results of heat transfer, breakdown voltage, aging stability and electrostatic charging tendency of different mixtures based on the mineral oil, silicon oil and synthetic ester. It was shown that the best mixture enabling optimization of the power transformer insulation is a mixture containing $20 \%$ synthetic ester and $80 \%$ mineral oil. Rao et al. [22] presented research results of the $80 \%$ mineral oil and $20 \%$ synthetic ester mixture in the field of thermal aging processes. The main purpose of the work was to lower the cost of transformer insulation liquid having a good thermal performance and improved oxidation stability. The authors observed that the oxidation rate of the blend of mineral oil with synthetic ester is lower than mineral oil. Yu at al. [23] presented the research results of the electrical and physicochemical parameters of dielectric liquid mixtures based on Envirotemp FR3 natural ester and Karamay No. 25 mineral oil. The tests showed that, with an increase of the natural ester concentration in the mixture, the pour point, acidy, dynamic viscosity, and AC breakdown voltage increased. Beroual et al. [24] showed the test results of AC and DC breakdown voltage of different mixtures based on Midel 7131 synthetic ester, Envirotemp FR3 natural ester and mineral oil. The authors confirmed that the increase in the concentration of both types of esters in a mixture with mineral oil always increases the electrical strength. It has been suggested that transformer retrofilling can be considered with mixtures composed of ester oil (80\%) and mineral oil (20\%). Hamadi et al. [25] presented a study on the electrical and thermal stability of mixtures of Borak 22 mineral oil and Midel 7131 synthetic ester. The authors showed that the use of synthetic ester in a mixture with mineral oil effectively slows down aging processes of insulating liquids. Dombek and Gielniak [26] investigated the effect of the mixture composition of Nynas Draco mineral oil and Midel 7131 synthetic ester with Envirotemp FR3 natural ester on the flash point, fire point, net calorific value, breakdown voltage, relative permittivity, dissipation factor and conductivity. The authors showed that the content of the mixture significantly determines the change of the tested parameters. Nadolny et al. $[27,28]$ presented the research results of thermal properties of Nytro Taurus mineral oil with Envirotemp FR3 natural ester and Midel 7131 synthetic ester mixtures. The authors showed the measurement results of thermal conductivity, viscosity, specific heat, density, and thermal expansion of the created mixtures in a wide temperature range. The authors showed that the increase in the concentration of esters in the mixture with mineral oil deteriorates the transformer cooling.

\subsection{Streaming Electrification Measurement Methods}

Another group of issues are ECT tests of the insulating liquids. For this purpose, a number of measurement methods were prepared to evaluate the risk of streaming electrification in the insulation of transformers. Gao et al. [29] have developed a measurement system with a closed insulating liquid circulation, to simulate the oil flow in a transformer. The electrification current was generated in an insulation system model. The current value was changing depending on the flow rate and 
the temperature of the mineral oil, and also depending on the values of the DC voltage applied. Zdanowski [30] has prepared a flow system that makes it possible to test the streaming electrification depending on the type of the metering pipe material, the flow rate, and the temperature of the insulating fluid. Zmarzły and Fracz [31,32] created measuring systems with a plate and an oscillating cylinder. In these systems, the electrification current can be measured in relation to the oscillation frequency of the measuring electrode. Ren et al. [33] used a modified mini-static tester to test electrification. In this system, the electrification current was generated as a result of a flowing sample of mineral oil with a volume of $50 \mathrm{~mL}$ at a speed of $1.2 \mathrm{~m} / \mathrm{s}$ through a cellulose filter. Leblanc et al. [34] used a measurement system with a capillary pipe, developed at the PPRIME institute (Poitiers, France). In this case, two electrometers were used, one of which would measure the leakage of electrical charges from the capillary pipe, and the other from a metal vessel placed in a Faraday cage. Zmarzły and Kędzia [35] prepared a system with a rotating electrometer, which makes it possible to record $1 / \mathrm{f}$ noise generated by the streaming electrification phenomenon. The electrification current signal obtained could be analyzed in the time domain, frequency domain, and in the time-frequency domain. Zdanowski et al. [36] developed a measurement system with a rotating disc to evaluate the ECT in insulating liquids. The electrification current was measured with an electrometer connected to a tank, in which the disc was placed submerged in the insulating liquid. Electrical charges were generated as a result of the disc being put into rotary motion. In the system, it is possible to measure the electrification current in relation to the rotation time, the diameter, and the rotation speed of the disc. For the disc system, an electrification model was developed, which makes it possible to determine the $q_{w}$ charge volume density at the interface between the disc and the liquid. This parameter is a material indicator used to evaluate and compare the ECT of insulating liquids. The main advantages of the disc system is its simple design, the ease of balancing the disc dynamically, the small volume of the liquid being tested, and the possibility of measuring the current continuously.

\subsection{Purpose and Scope of Research}

This paper is another stage of the author's research works related to the streaming electrification of insulating liquid mixtures. Zdanowski and Maleska [37,38] showed a high correlation between the electrification current and the composition of Trafo EN mineral oil mixtures with Envirotemp FR3 natural ester, Midel 1204 natural ester and Midel 7131 synthetic ester. The electrification current characteristics significantly depended on the type of mineral oil used in the tests (fresh or aged). The minimum and maximum of the electrification current were observed. This time, the subject was to evaluate the ECT of mixtures of Nycodiel 1255 synthetic ester with fresh and aged Trafo EN mineral oil. Their main purpose of the paper was to specify the most beneficial composition of the mixture in terms of retrofilling transformers. The tests were performed in a rotating disc system, designed and built by the author. In the first stage of the study, the impact of the mixture's composition on its density, kinematic viscosity, molecular diffusion coefficient, conductivity, and relative dielectric constant was determined. Then, the impact of the rotation time, the rotation speed, and the disc's diameter on the electrification current generation in the insulating liquid was examined. In the next stage, the impact of the composition of the mixture of synthetic ester with fresh and aged mineral oil on the form of the electrification current was analyzed. Based on the measurements of the physicochemical and electrical properties, and of the electrification current, the volume density of the $q_{w}$ charge was determined using the electrification model, which is a parameter defining the ECT of insulating liquids. The key conclusion from the studies is that a small amount (up to 20\%) of fresh and aged Trafo EN effectively reduces the electrification of Nycodiel 1255 synthetic ester. The results show that replacing mineral oil with synthetic ester reduces the risk of streaming electrification in the insulation system of transformers. Running diagnostic tests for the streaming electrification phenomenon may help reduce the effects of possible failures, and thus shorten the time and reduce the costs of repairing power transformers. 


\section{Materials and Methods}

To prepare the insulating liquid mixtures, Trafo EN (MO) mineral oil from Orlen Oil (Krakov, Poland), and Nycodiel 1255 (SE) synthetic ester from Cargil (Paris, France) were used. In order to simulate the ageing processes that take place in the course of a power transformer's operation, the mineral oil was subjected to accelerated thermal ageing according to standard IEC 1125 (Method C: $164 \mathrm{~h}, 120 \mathrm{C}$, copper catalyst $-1144 \mathrm{~cm}^{2} / \mathrm{kg}$ of oil, air- $0.15 \mathrm{~L} / \mathrm{h}$ ). The mixtures based on the synthetic ester, and on the fresh and aged mineral oil were prepared at an ambient temperature, and then cured in tightly sealed bottles for a month. The liquids was mixed with the aid of a magnetic stirrer at a speed of $1100 \mathrm{rpm}$ for about $60 \mathrm{~min}$, according to the procedure proposed by Beroual et al. [24]. The mixture's volume was $1000 \mathrm{~mL}$, and its composition was changing by $10 \%$. The fluid's density was determined by means of a universal glass densimeter according to standard ISO 3675. The kinematic viscosity was measured with a Brookfield DV-II + Pro viscometer on the basis of standard ISO 2555. The electrical parameters were determined according to standard IEC 60,247 with the use of a tri-electrode capacitor. The conductivity was determined by measuring the resistivity with an MR0-4c meter. The relative dielectric constant was determined by measuring the electrical capacity with a Hioki 3522-50 LCR HiTester meter. The molecular diffusion coefficient was determined based on the empirical dependency (1) specified by Adamczewski [39]:

$$
D_{m}=\frac{3.93 \times 10^{-14} \cdot T}{v_{k} \rho}
$$

where $T$ is temperature, $v_{k}$ kinematic viscosity, and $\rho$ density.

Figure 1 presents the rotating disc system for measuring the electrification current of insulating liquids. The system consisted of an air-tight measurement vessel with a diameter of $100 \mathrm{~mm}$, filled with $500 \mathrm{~mL}$ of the liquid, placed on a Teflon insulator. In the vessel, metal discs were installed with diameters of 50, 60, 70, and $80 \mathrm{~mm}$. The discs' rotation speed within the range from 100 to $500 \mathrm{rpm}$ was regulated by means of a type 57BYGH step motor, combined with a system with a controller and a display. Each disc was connected with the motor by means of a metal mandrel, and an isolating clutch, serving as a mechanical and electric separator. The whole system was placed in a metal casing, serving the role of a Faraday cage. The rotary motion of the disc generated electrostatic charges, and their leakage to the ground was measured with a Keithley 6517A electrometer. The half-rack-sized model 6517A has a special low current input amplifier with an input bias current of $<3 \mathrm{fA}$ with just $0.75 \mathrm{fA}$ p-p (peak-to-peak) noise and $<20 \mu \mathrm{V}$ burden voltage on the lowest range. The electrometer allows the measurement of current in the range $1 \mathrm{fA}$ to $20 \mathrm{~mA}$. The measurement process was controlled by means of a dedicated software application [40] installed on a portable computer. The measurement process consisted in washing and de-greasing the disc carefully, and then in seasoning it for two hours in the liquid being tested, to stabilize the hydrodynamic and electric conditions in the measuring system. During the tests, the air temperature in the lab was at a level of approx. $20^{\circ} \mathrm{C}$. Each point on the current characteristics chart is the average of the 500 values obtained from five measurement series, each of which lasted for $100 \mathrm{~s}$. The error bars were determined based on the average electrification current, the standard deviation, and the significance level $\alpha=0.05$. The streaming electrification phenomenon in the measuring system starts to grow as a result of an increase in the disc's rotation speed. Due to the liquid's very complex motion in the measurement vessel, during the disc's activation, transient states are observed, characterized by considerable fluctuations in the form of the electrification current. The transitional processes result from a fast increase in the disc's speed in respect to the adjacent liquid. This results in a lot of slippage, a consequence of which is a rapid growth in the electrification current. This condition disappears within seconds after the speed of the disc and of the adjacent liquid layer become equal. Zmarzły [35] has analyzed the electrification current signal in the transient state. Because of the limited metering capabilities of the Keithley 6517A electrometer applied, the article presents the measurement results, which were recorded after the transient states disappeared. 


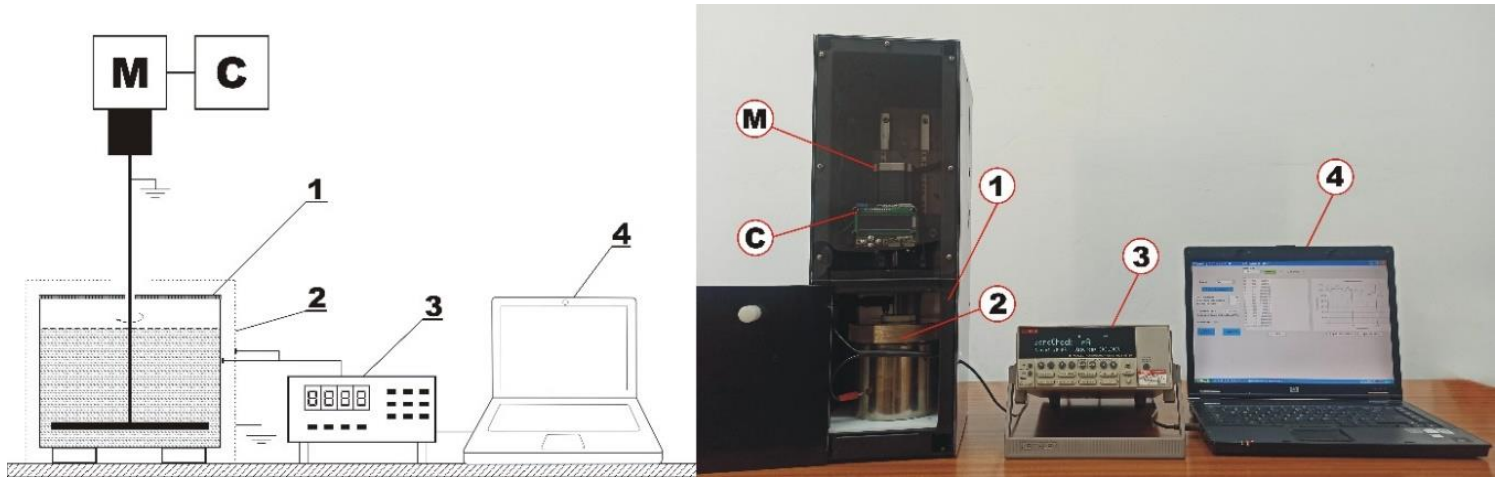

Figure 1. Rotating disc system for the investigation of electrification current of insulation liquids: 1-measuring vessel with liquid and disc, 2-Faraday cage, 3-Keithley 6517A electrometer,

4-portable computer, $\mathrm{M}$-stepper motor and C—controller with display.

\section{Mathematical Model of the Streaming Electrification Phenomenon}

The impact of the hydrodynamic conditions and of the physicochemical properties of the insulation liquids on the electrification process in the rotating disc system is described with the use of the model developed by Kędzia [41]. The liquid's motion in the system being discussed is very complex. The liquid adjacent to the disc moves with the disc's angular speed. The centrifugal forces create the liquid's component speeds in the radial direction. At the measurement vessel's wall, the liquid moves vertically. Then, the liquid moves over the disc's upper and lower surface towards its axis. The current in the measurement circuit is the sum of the diffusion current from the $q_{w}$ charge spread across the vessel's and the disc's surface, the diffusion current from the $q_{0}$ charge introduced by the disc's rotational movement into the volume of the liquid, and the conductivity current, flowing in the liquid as a result of the electric field created by the charge in the liquid. In the model, it was assumed that the liquid's speed profile is fully developed. It was also assumed that the volumetric density of the $q_{w}$ charge in the double electrical layer depends only on the properties of the liquid and of the solid, and does not depend on the hydrodynamic conditions. For this reason, the $q_{w}$ parameter can be used to determine and compare the ECT of insulating liquids. The electrification current in the disc system is described with the use of the Equation (2):

$$
I=\frac{\sigma q_{w} V}{\varepsilon_{0} \varepsilon_{r} A}+\frac{D_{m} q_{w}}{\delta A} S_{d}-\frac{D_{m} q_{w}}{\delta} S_{d}
$$

Constant $A$ is given by the Equation (3):

$$
A=\frac{q_{w}}{q_{0}}=1+\frac{\delta V}{\lambda^{2} S}
$$

The thickness of the laminar sublayer is described by the Equation (4):

$$
\delta=\frac{B v_{k}}{S_{n}{ }^{\frac{1}{C}}\left(\frac{\tau_{w}}{\rho}\right)^{0.5}}
$$

The Debye length can be determined from Equation (5):

$$
\lambda=\sqrt{\frac{D_{m} \varepsilon_{0} \varepsilon_{r}}{\sigma}}
$$

The shear stresses are given by Equation (6):

$$
\tau_{w}=0.0396 R e^{-0.25} \rho v^{2}
$$


The Reynolds number is given by Equation (7):

$$
\operatorname{Re}=\frac{\omega R^{2}}{v_{k}}
$$

where $I$ denotes the electrification current, $q_{w}$-volume charge density on the phase border, $q_{0}$-volume charge density in the liquid volume, $\sigma$-conductivity, $\rho$-density, $v_{k}$-kinematic viscosity, $\varepsilon_{0}$-vacuum electric permittivity, $\varepsilon_{r}$-relative dielectric constant, $D_{m}$-molecular diffusion coefficient, $\delta$-laminar sublayer thickness, $\tau_{w}$-shearing stress, $\lambda$-Debye length, $\omega$-angular velocity, $v$-average velocity, $R e$-Reynolds number, $V$-liquid volume, $R$-disc radius, $S_{d}$-disc surface, $S$-disk and container surface, $S_{n}$-Schmidt number $\left(S_{n}=v_{k} / D_{m}\right)$, and $A, B, C$ - constant $\left(A=q_{w} / q_{0}, B=11.7 ; C=3\right)$.

\section{Results}

The density and viscosity are among the most important indicators describing the physicochemical properties of liquid dielectrics. The density of an insulating liquid is used in design calculations to determine a transformer's weight, and the viscosity determines the cooling effectiveness of its active parts. Liquids with lower viscosity are more effective at removing heat from the inside of a transformer into the environment. The conductivity and viscosity depend to a significant extent on the temperature, and thus they affect other properties of the insulating liquids, which include the carrier mobility, molecular diffusion coefficient, relative dielectric constant, and charge relaxation time. The relative dielectric constant influences the stress distribution in a transformer's insulation system, and thus it determines its electric durability [26-28]. When analyzing the data contained in Tables 1 and 2, it can be observed that the ageing processes affect to a different extent the physicochemical and electrical properties of Trafo EN mineral oil. The changes in the density $(\rho)$ and in the relative dielectric constant $\left(\varepsilon_{r}\right)$ do not exceed $1 \%$. The kinematic viscosity $\left(v_{k}\right)$ is characterized by a $9 \%$ increase, and the molecular diffusion coefficient $\left(D_{m}\right)$ shows a 10\% drop. The largest differences are visible in the conductivity $(\sigma)$, the value of which increases by nearly two orders of magnitude. And when comparing Nycodiel 1255 synthetic ester with Trafo EN mineral oil, we can see that the ester is characterized by a higher density, kinematic viscosity, conductivity, relative dielectric constant, and a lower molecular diffusion coefficient.

Table 1. Properties of Nycodiel 1255 synthetic ester and fresh Trafo EN mineral oil mixtures $\left(20^{\circ} \mathrm{C}\right)$.

\begin{tabular}{cccccc}
\hline Mixture Content & $\boldsymbol{\rho}\left(\mathbf{k g} / \mathbf{m}^{3}\right)$ & $\boldsymbol{v}_{\boldsymbol{k}}\left(\mathbf{m}^{\mathbf{2}} \mathbf{s}\right)$ & $\boldsymbol{D}_{\boldsymbol{m}}\left(\mathbf{m}^{\mathbf{2}} / \mathbf{s}\right)$ & $\boldsymbol{\sigma}(\mathrm{S} / \mathbf{m})$ & $\boldsymbol{\varepsilon}_{\boldsymbol{r}}(-)$ \\
\hline SE 100\% & 970 & $6.21 \times 10^{-5}$ & $1.31 \times 10^{-11}$ & $7.85 \times 10^{-12}$ & 3.19 \\
$90 \% \mathrm{SE}+10 \% \mathrm{MO}$ & 963 & $5.63 \times 10^{-5}$ & $1.45 \times 10^{-11}$ & $6.41 \times 10^{-12}$ & 3.09 \\
$80 \% \mathrm{SE}+20 \% \mathrm{MO}$ & 952 & $4.95 \times 10^{-5}$ & $1.67 \times 10^{-11}$ & $4.90 \times 10^{-12}$ & 2.97 \\
$70 \% \mathrm{SE}+30 \% \mathrm{MO}$ & 941 & $4.55 \times 10^{-5}$ & $1.84 \times 10^{-11}$ & $4.02 \times 10^{-12}$ & 2.88 \\
$60 \% \mathrm{SE}+40 \% \mathrm{MO}$ & 932 & $3.99 \times 10^{-5}$ & $2.11 \times 10^{-11}$ & $3.02 \times 10^{-12}$ & 2.76 \\
$50 \% \mathrm{SE}+50 \% \mathrm{MO}$ & 923 & $3.63 \times 10^{-5}$ & $2.35 \times 10^{-11}$ & $2.58 \times 10^{-12}$ & 2.66 \\
$40 \% \mathrm{SE}+60 \% \mathrm{MO}$ & 911 & $3.19 \times 10^{-5}$ & $2.70 \times 10^{-11}$ & $2.01 \times 10^{-12}$ & 2.57 \\
$30 \% \mathrm{SE}+70 \% \mathrm{MO}$ & 902 & $2.93 \times 10^{-5}$ & $2.97 \times 10^{-11}$ & $1.55 \times 10^{-12}$ & 2.45 \\
$20 \% \mathrm{SE}+80 \% \mathrm{MO}$ & 891 & $2.69 \times 10^{-5}$ & $3.28 \times 10^{-11}$ & $1.32 \times 10^{-12}$ & 2.36 \\
$10 \% \mathrm{SE}+90 \% \mathrm{MO}$ & 881 & $2.37 \times 10^{-5}$ & $3.77 \times 10^{-11}$ & $9.88 \times 10^{-13}$ & 2.26 \\
MO 100\% & 871 & $2.21 \times 10^{-5}$ & $4.11 \times 10^{-11}$ & $7.97 \times 10^{-13}$ & 2.19 \\
\hline
\end{tabular}


Table 2. Properties of Nycodiel 1255 synthetic ester and aged Trafo EN mineral oil mixtures $\left(20^{\circ} \mathrm{C}\right)$.

\begin{tabular}{|c|c|c|c|c|c|}
\hline Mixture Content & $\rho\left(\mathrm{kg} / \mathrm{m}^{3}\right)$ & $v_{k}\left(\mathrm{~m}^{2} / \mathrm{s}\right)$ & $D_{m}\left(\mathrm{~m}^{2} / \mathrm{s}\right)$ & $\sigma(\mathrm{S} / \mathrm{m})$ & $\varepsilon_{r}(-)$ \\
\hline SE $100 \%$ & 970 & $6.21 \times 10^{-5}$ & $1.31 \times 10^{-11}$ & $7.85 \times 10^{-12}$ & 3.19 \\
\hline $90 \% \mathrm{SE}+10 \% \mathrm{MO}$ & 962 & $5.65 \times 10^{-5}$ & $1.45 \times 10^{-11}$ & $8.29 \times 10^{-12}$ & 3.11 \\
\hline $80 \% \mathrm{SE}+20 \% \mathrm{MO}$ & 951 & $5.29 \times 10^{-5}$ & $1.56 \times 10^{-11}$ & $8.61 \times 10^{-12}$ & 2.99 \\
\hline $70 \% \mathrm{SE}+30 \% \mathrm{MO}$ & 940 & $4.71 \times 10^{-5}$ & $1.78 \times 10^{-11}$ & $9.21 \times 10^{-12}$ & 2.92 \\
\hline $60 \% \mathrm{SE}+40 \% \mathrm{MO}$ & 931 & $4.35 \times 10^{-5}$ & $1.94 \times 10^{-11}$ & $9.72 \times 10^{-12}$ & 2.81 \\
\hline $50 \% \mathrm{SE}+50 \% \mathrm{MO}$ & 922 & $3.99 \times 10^{-5}$ & $2.14 \times 10^{-11}$ & $1.02 \times 10^{-11}$ & 2.72 \\
\hline $40 \% \mathrm{SE}+60 \% \mathrm{MO}$ & 910 & $3.62 \times 10^{-5}$ & $2.40 \times 10^{-11}$ & $1.07 \times 10^{-11}$ & 2.63 \\
\hline $30 \% \mathrm{SE}+70 \% \mathrm{MO}$ & 901 & $3.21 \times 10^{-5}$ & $2.72 \times 10^{-11}$ & $1.14 \times 10^{-11}$ & 2.52 \\
\hline $20 \% \mathrm{SE}+80 \% \mathrm{MO}$ & 889 & $2.98 \times 10^{-5}$ & $2.97 \times 10^{-11}$ & $1.19 \times 10^{-11}$ & 2.41 \\
\hline $10 \% \mathrm{SE}+90 \% \mathrm{MO}$ & 880 & $2.75 \times 10^{-5}$ & $3.25 \times 10^{-11}$ & $1.27 \times 10^{-11}$ & 2.35 \\
\hline MO $100 \%$ & 870 & $2.41 \times 10^{-5}$ & $3.77 \times 10^{-11}$ & $1.33 \times 10^{-11}$ & 2.29 \\
\hline
\end{tabular}

For example, Figures $2 a-c$ and $3 a, b$ present the dependencies that describe the impact of the percentage share of fresh Trafo EN mineral oil and Nycodiel 1255 synthetic ester in the mixtures on the change in the physicochemical and electric parameters. An increase in the content of the mineral oil in the mixture with the synthetic ester caused a linear drop in the density (Figure 2a), and in the relative dielectric constant (Figure 3b), and a non-linear drop in the kinematic viscosity (Figure 2b), and in the conductivity (Figure 3a), and also a non-linear increase in the molecular diffusion coefficient (Figure 2c). Similar parameters are demonstrated by both mixtures of Envirotemp FR3 natural ester with Nytro Taurus [27] and Trafo EN [37] mineral oils, and also mixtures of Midel 7131 synthetic ester with Nytro Draco [26] and Nytro Taurus [28] mineral oils.

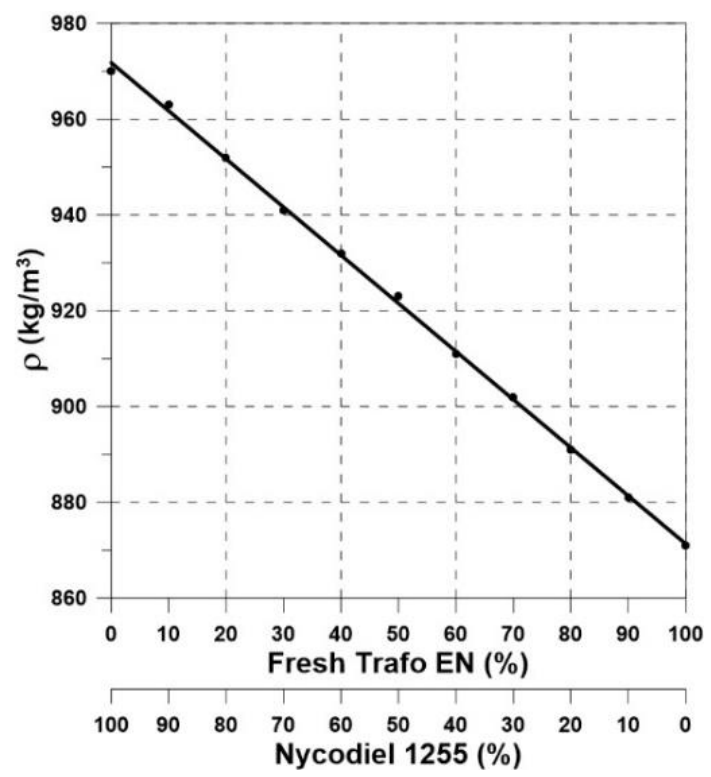

(a)

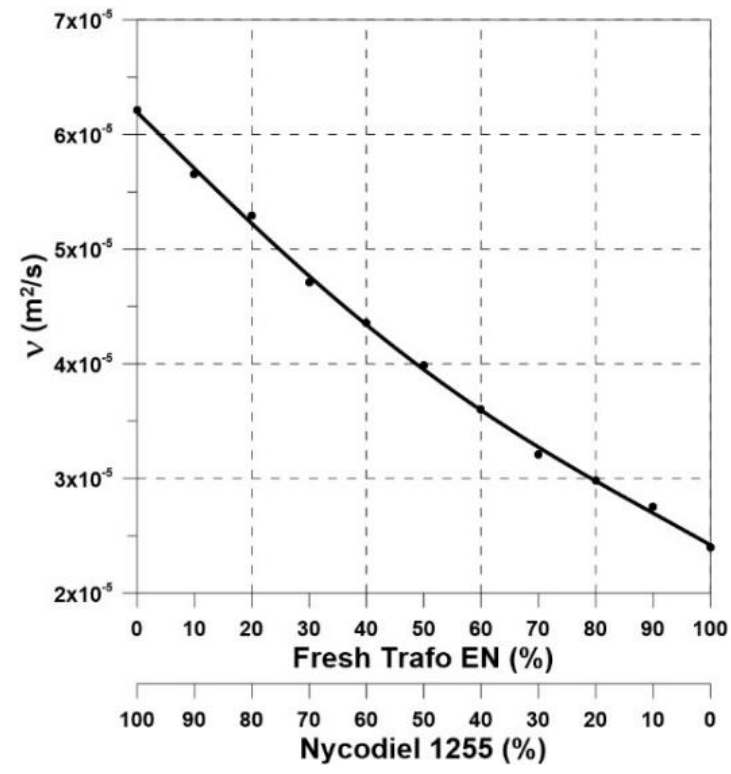

(b)

Figure 2. Cont. 


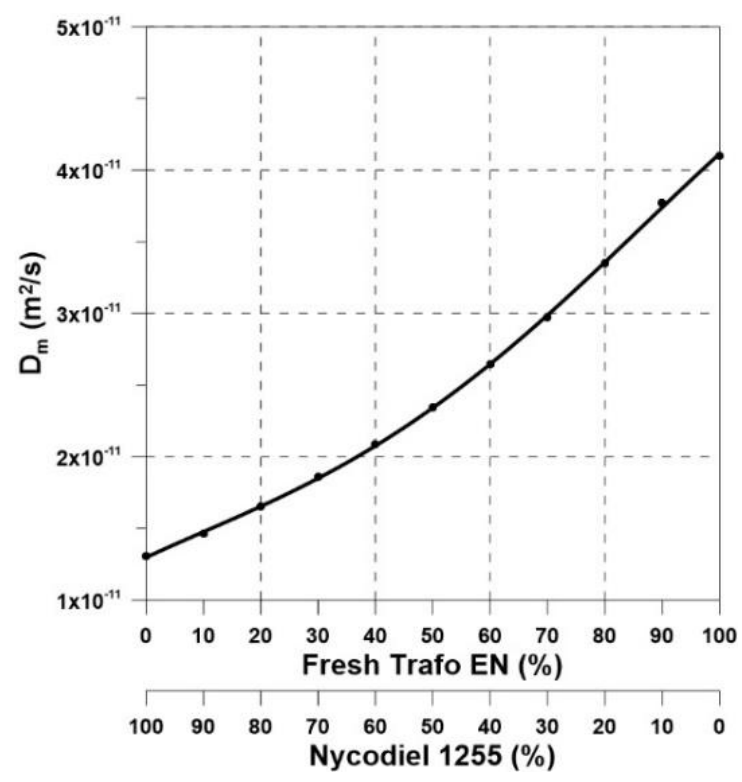

(c)

Figure 2. (a) Density, (b) kinematic viscosity and (c) molecular diffusion coefficient vs. mixing of Nycodiel 1255 synthetic ester with fresh Trafo EN mineral oil.

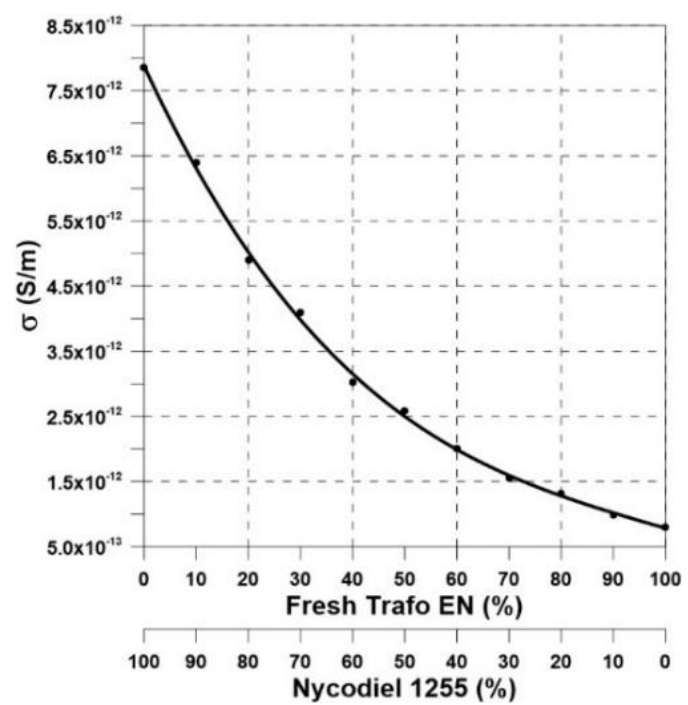

(a)

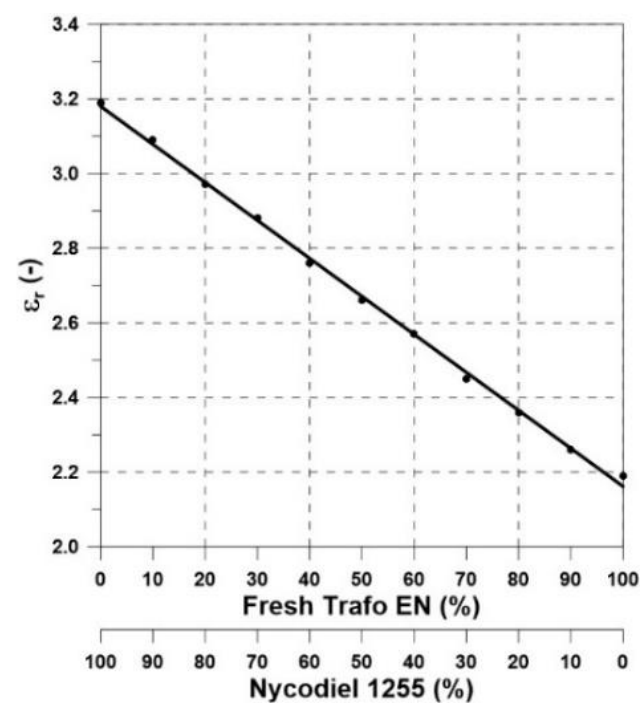

(b)

Figure 3. (a) Conductivity and (b) relative dielectric constant vs. mixing of Nycodiel 1255 synthetic ester with fresh Trafo EN mineral oil.

To sum up, it should be concluded that comparing the properties of synthetic esters with those of mineral oils is important from the point of view of retrofilling power transformers. It is difficult to clearly indicate, which of the insulating liquids discussed is better or worse for use in transformers. The synthetic esters and mineral oils show a number of desired properties, unfortunately they are not free from disadvantages. Undoubtedly, the use of the synthetic esters is supported by environmental and fire safety aspects, and thus the interest in these liquids increases.

Figure 4a presents the electrification current characteristics of the synthetic ester in relation to the rotation time of the discs with different diameters $(50,60,70,80 \mathrm{~mm})$ at a speed of $500 \mathrm{rpm}$. A change in the disc's rotation speed within the range from 50 to $500 \mathrm{rpm}$ results in a non-linear increase in the electrification current of Nycodiel 1255 insulating liquid (Figure 4b). It was observed 
that the diameter and the rotation speed of the discs are factors that significantly influence the hydrodynamic conditions in the measurement system, and thus they affect the generation of the streaming electrification phenomenon.

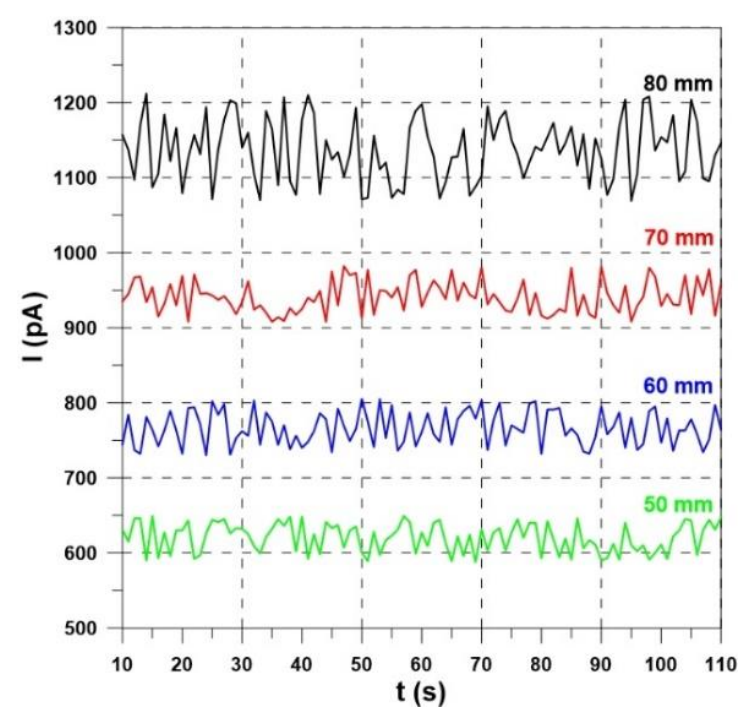

(a)

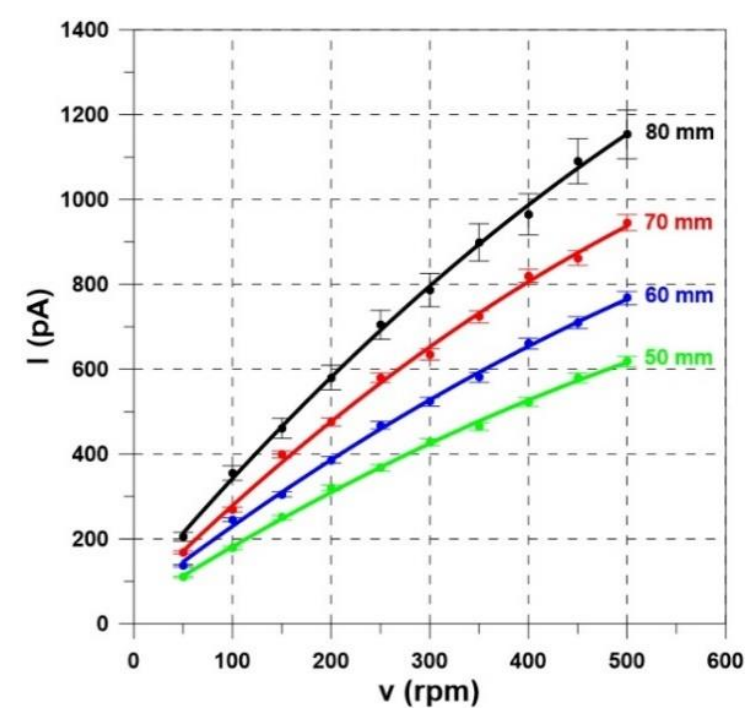

(b)

Figure 4. Electrification current of Nycodiel 1255 synthetic ester vs. (a) rotating time $(v=500 \mathrm{rpm})$ and (b) rotational velocity for discs of different diameters $(d=50,60,70,80 \mathrm{~mm})$.

Figure 5a presents the dependencies between the electrification current in fresh and aged Trafo EN mineral oil, and Nycodiel 1255 synthetic ester depending on the rotation speed of the disc with the diameter of $80 \mathrm{~mm}$. For each of the liquids, a non-linear increase in the electrification current is observed. The fresh mineral oil electrifies the least. The ageing processes in the mineral oil increase its electrification tendency. The synthetic ester shows an electrification nearly three times higher than that of the fresh Trafo EN oil. At the highest rotation speed $(v=500 \mathrm{rpm})$ of the disc $(d=80 \mathrm{~mm})$, the electrification current was $417 \mathrm{pA}$ (fresh Trafo EN oil), $854 \mathrm{pA}$ (aged Trafo EN oil), and $1154 \mathrm{pA}$ (Nycodiel 1255), respectively. Figure 5b presents the impact of the disc's rotation speed on the volume density of the $q_{w}$ charge. The average $q_{w}$ valueis $0.036 \mathrm{C} / \mathrm{m}^{3}$ (fresh Trafo EN oil), $0.065 \mathrm{C} / \mathrm{m}^{3}$ (aged Trafo EN oil), $0.192 \mathrm{C} / \mathrm{m}^{3}$ (Nycodiel 1255), respectively. When analyzing the charts, it may be stated that this parameter depends to a significant extent on the insulating liquid type. On the other hand, it does not depend on the hydrodynamic conditions prevailing in the measuring system, which is confirmed by its usefulness in determining the ECT of liquid dielectrics. As the study shows, the chemical structure of a liquid and the ageing processes can have a significant effect on the streaming electrification phenomenon in power transformers. In addition, as a result of retrofilling a transformer, a mixture is generated inside with electrostatic features that can be different than those of each base fluid. 


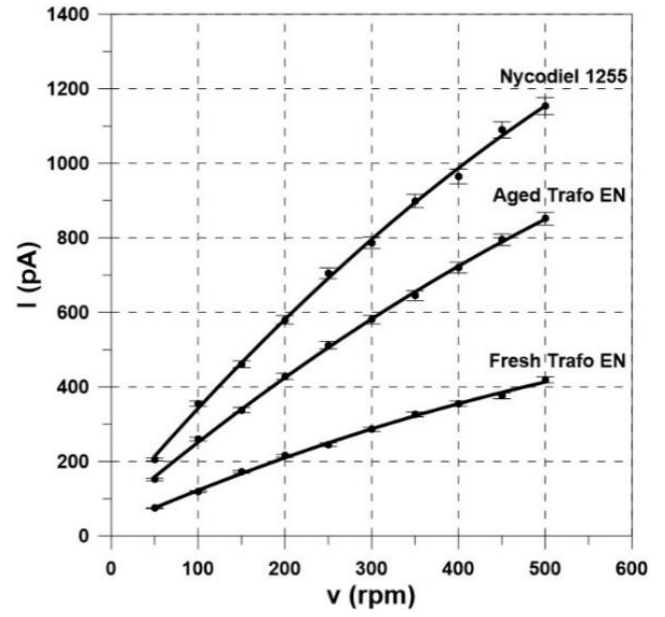

(a)

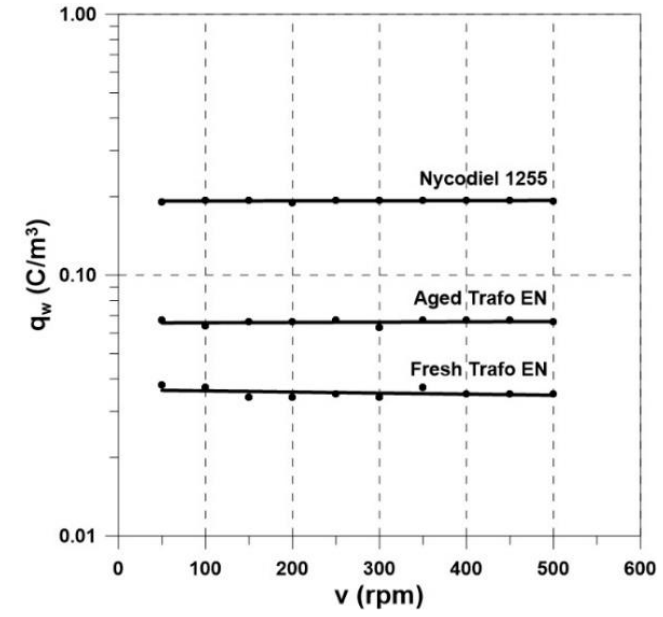

(b)

Figure 5. (a) Electrification current and (b) volume charge density $q_{w}$ of insulating liquids vs. rotational velocity of the disc $(d=80 \mathrm{~mm})$.

Figure 6a presents the impact of the composition of the mixtures of Nycodiel 1255 synthetic ester with Trafo EN mineral oil on the electrification current form. In the measurements, a disc with a diameter of $80 \mathrm{~mm}$ was used, rotating at a speed of $500 \mathrm{rpm}$. Significant differences in the form of the current characteristics were demonstrated, depending on the type of the mineral oil admixture (fresh or aged). In the first case, the electrification current decreases and reaches its minimum value (1011 pA), when the content of fresh oil in the mixture is $20 \%$. Increasing the volume of oil in the mixtures results in an intensive growth in the electrification current value. The current characteristic reaches its maximum value $(2613 \mathrm{pA})$ in the mixture consisting of $80 \%$ of mineral oil and $20 \%$ of synthetic ester. In the second case, the admixture of aged mineral oil of up to approx. $20 \%$ leads to lowering the electrification current value. Increasing the percentage share of mineral oil does not lead to any significant changes in the electrification current form anymore. Figure $6 \mathrm{~b}$ presents the dependencies between the $q_{w}$ charge volume density and the mixture's composition. The characteristics of the $q_{w}$ charge have a different form than the current characteristics, since the electrification model, apart from the electrification current, takes additionally account of the physical-chemical and electrical properties of the liquids being studied.

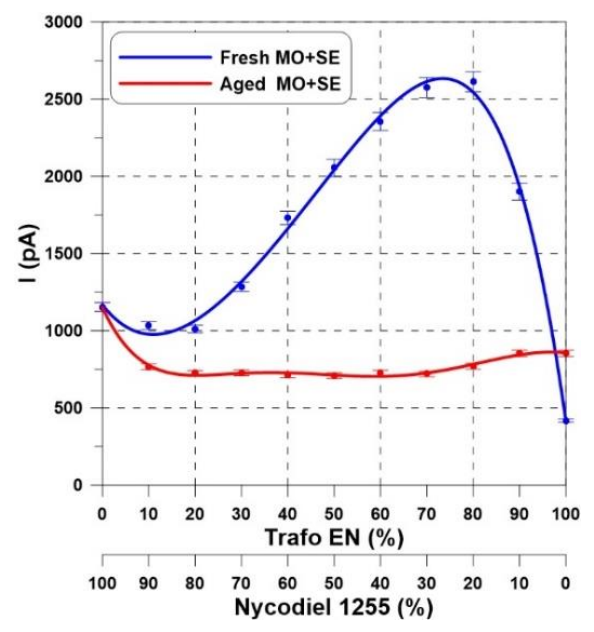

(a)

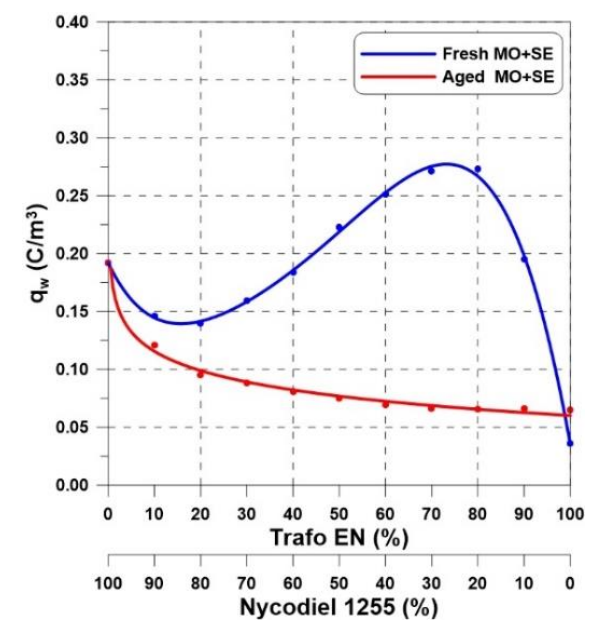

(b)

Figure 6. (a) Electrification current and (b) volume charge density $q_{w}$ vs. mixing of Nycodiel 1255 synthetic ester with fresh and aged Trafo EN mineral oil ( $v=500 \mathrm{rpm}, d=80 \mathrm{~mm})$. 
This leads to a significant conclusion that, in order to specify the ECT of insulating liquids, it is necessary to know both the electrification current and the properties of the liquids. In order to visualize the electrification current value, and the $q_{w}$ charge value for selected liquids, their results are presented in the form of bar charts (Figure 7a,b).

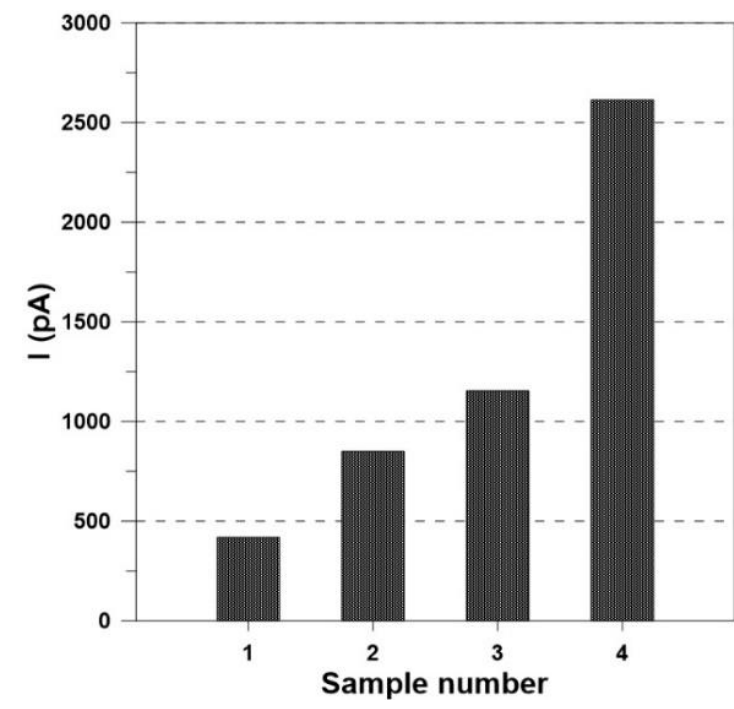

(a)

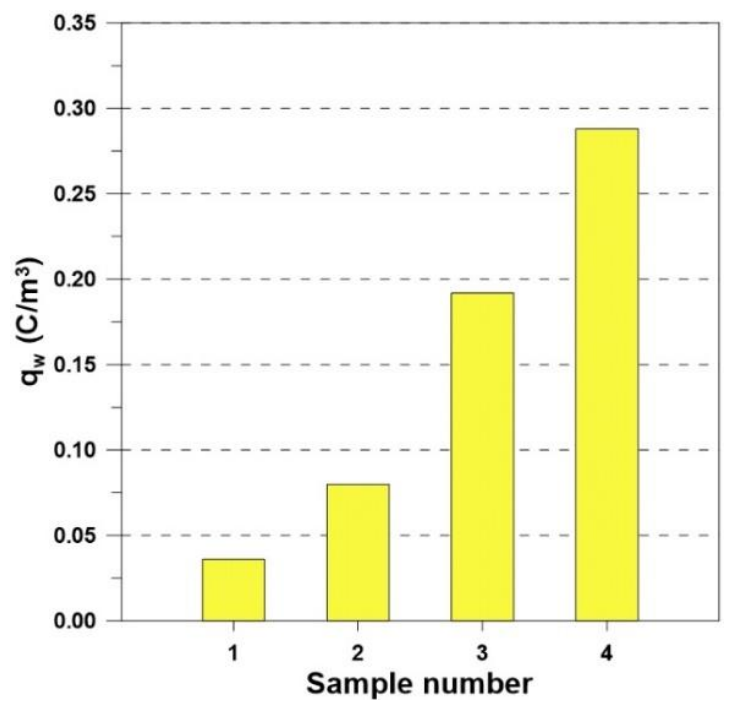

(b)

Figure 7. (a) Electrification current and (b) volume charge density $q_{w}$ of: 1 -fresh Trafo EN, 2-aged Trafo EN, 3-Nycodiel 1255, 4-20\% (SE) - $80 \%$ (fresh MO) mixture.

The tests performed demonstrated that the type of the mineral oil used (fresh or aged) and the percentage share of the particular components in the mixtures substantially contribute to the generation of the streaming electrification phenomenon. Similar dependencies between the parameters being studied were obtained for the mixtures of Trafo EN mineral oil with Envirotemp FR3 natural ester [37], and with Midel 1204 natural ester and Midel 7131 synthetic ester [38]. Rajab et al. [42] presented the results of their studies on the electrification in mixtures of PFAE (palm fatty acid ester) with fresh and used mineral oil. The authors also observed the characteristic maximum of the electrification current, when the content of PFAE was $80 \%$. It is difficult to clearly explain this phenomenon, since for the density, the kinematic viscosity, the conductivity, or the relative dielectric constant, no maximum or minimum values are observed. The reasons for this type of phenomena can result from different chemical structures of mineral oil and synthetic ester. These liquids differ in, for example, the capacity to absorb water from the environment, which may influence the structure of the electrical double layer, where the charge responsible for electrification in insulating liquids is created.

\section{Conclusions}

Due to their complex structure and the role they serve in an electric power system, power transformers should be properly diagnosed, which may be reflected in their effective, reliable, and long operation. For this reason, more often than before, when modernizing transformers, mineral oil is being replaced with synthetic or natural esters. The primary purpose of the paper was to specify the ECT of mixtures of fresh and aged Trafo EN mineral oil with Nycodiel 1255 synthetic ester in the context of retrofiling power transformers. The ECT of the insulating liquids were determined on the basis of the volume density of the $q_{w}$ charge created in the double electrical layer at the solid - liquid interface. The $q_{w}$ parameter was determined using the electrification model for the disc system, based on the measurements of the density, the kinematic viscosity, the molecular diffusion factor, the conductivity, the relative dielectric constant, and the electrification current in the mixtures. The parameters that affect the size of the electrification current generated are the rotation speed, the disc diameter, and the 
mixtures' composition. The study demonstrated that Nycodiel 1255 synthetic ester electrifies more than fresh and aged mineral oil. It was demonstrated that the ECT of the mixtures depends to a significant extent on their composition. The forms of the electrification current in the mixtures with fresh and aged mineral oil are essentially different. In the first case, the minimal electrification current is observed at $20 \%$ of oil in the mixture, and the maximum when the oil content reaches $80 \%$. Aged mineral oil $(20 \%)$ in the mixtures reduces the electrification current value. A further increase in the aged oil content in a mixture with synthetic ester causes no further significant changes in the electrification current. In both the first and second cases, a small amount of Trafo EN mineral oil (up to 20\%) effectively reduces the ECT of Nycodiel 1255 synthetic ester. The most important conclusion of the study conducted is the observation that replacing mineral oil with synthetic ester does not increase the risk of streaming electrification in the insulation system of power transformers. This phenomenon is beneficial for transformer retrofilling.

Funding: This research received no external funding.

Conflicts of Interest: The authors declare no conflict of interest.

\section{References}

1. Boss, P.; Lorin, P.; Viscardi, A.; Harley, J.W.; Isecke, J. Economical aspects and experiences of power transformer on-line monitoring. In CIGRE Session 2000; CIGRE: Paris, France, 2000.

2. The Council on Large Electric Systems (CIGRE). CIGRE Technical Brochure 248; Economics of Transformer Management; CIGRE: Paris, France, 2004.

3. Fofana, I.; Borsi, H.; Gockenbach, E.; Farzaneh, M. Aging of transformer insulating materials under selective conditions. Electr. Energy Syst. 2007, 17, 450-470. [CrossRef]

4. Martin, D.; Cui, Y.; Ekanayake, C.; Ma, H.; Saha, T. An updated model to determine the life remaining of transformer insulation. IEEE Trans. Power Deliv. 2015, 30, 395-402. [CrossRef]

5. Ruan, J.; Jin, S.; Du, Z.; Xie, Y.; Zhu, L.; Tian, Y.; Gong, R.; Li, G.; Xiong, M. Condition assessment of paper insulation in oil-immersed power transformers based on the iterative inversion of resistivity. Energies 2017, 10, 509. [CrossRef]

6. Wolny, S. Analysis of high-frequency dispersion characteristics of capacitance and loss factor of aramid paper impregnated with various dielectric liquids. Energies 2019, 12, 1063. [CrossRef]

7. Fofana, I. 50 years in the development of insulating liquids. IEEE Electr. Insul. Mag. 2013, 29, 13-25. [CrossRef]

8. N'cho, J.S.; Fofana, I.; Hadjadj, Y.; Beroual, A. Review of physicochemical-based diagnostic techniques for assessing insulation condition in aged transformers. Energies 2016, 9, 367. [CrossRef]

9. Wang, X.; Tang, C.; Huang, B.; Hao, J.; Chen, G. Review of research progress on the electrical properties and modification of mineral insulating oils used in power transformers. Energies 2018, 11, 487. [CrossRef]

10. Fernández, I.; Ortiz, A.; Delgado, F.; Renedo, C.; Pérez, S. Comparative evaluation of alternative fluids for power transformers. Electr. Power Syst. Res. 2013, 98, 58-69. [CrossRef]

11. Mohan Rao, U.; Fofana, I.; Jaya, T.; Rodriguez-Celis, E.M.; Jalbert, J.; Picher, P. Alternative dielectric fluids for transformer insulation system: Progress, challenges, and future prospects. IEEE Access 2019, 7, 184552-184571. [CrossRef]

12. Mehta, D.M.; Kundu, P.; Chowdhury, A.; Lakhiani, V.K.; Jhala, A.S. A review on critical evaluation of natural ester vis-a-vis mineral oil insulating liquid for use in transformers: Part 1. IEEE Trans. Dielectr. Electr. Insul. 2016, 23, 873-880. [CrossRef]

13. Mehta, D.M.; Kundu, P.; Chowdhury, A.; Lakhiani, V.K.; Jhala, A.S. A review on critical evaluation of natural ester vis-a-vis mineral oil insulating liquid for use in transformers: Part II. IEEE Trans. Dielectr. Electr. Insul. 2016, 23, 1705-1712. [CrossRef]

14. Shinde, R. Condition monitoring of a retro-filled power transformer by natural ester Envirotemp FR3 fluid. In Proceedings of the 3rd International Conference on Condition Assessment Techniques in Electrical Systems (CATCON), Rupnagar, India, 16-18 November 2017; pp. 265-269.

15. Rajaram, S.; Naveen, J. Maintenance of natural ester (Envirotemp FR3 dielectric fluid) filled transformer. J. Int. Assoc. Electr. Gener. Trans. Distr. 2018, 31, 22-25. 
16. Zhao, Y.; Qian, Y.; Wei, B.; Wang, R.; Rapp, K.J.; Xu, Y. In-service ageing comparison study of natural ester and mineral oil filled distribution transformers. In Proceedings of the IEEE International Conference on Dielectric Liquids (ICDL), Roma, Italy, 23-27 June 2019.

17. Breazeal, R.C.; Sbravati, A.; Robalino, D.M. Evaluation of natural ester retrofilled transformers after one year of continuous overload. In Proceedings of the Electrical Insulation Conference (EIC), Calgary, AB, Canada, 16-19 June 2019; pp. 115-119.

18. McShane, C.P.; Luksich, J.; Rapp, K.J. Retrofilling aging transformers with natural ester based dielectric coolant for safety and life extension. In Proceedings of the Cement Industry Technical Conference, Conference Record IEEE-IAS/PCA, Dallas, TX, USA, 4-9 May 2003; pp. 141-147.

19. Fofana, I.; Wasserberg, V.; Borsi, H.; Gockenbach, E. Challenge of mixed insulating liquids for use in high-voltage transformers Part 1: Investigation of mixed liquids. IEEE Elect. Insul. Mag. 2002, 18, 18-31. [CrossRef]

20. Fofana, I.; Wasserberg, V.; Borsi, H.; Gockenbach, E. Challenge of mixed insulating liquids for use in high-voltage transformers Part 2: Investigations of mixed liquid impregnated paper insulation. IEEE Electr. Insul. Mag. 2002, 18, 5-16. [CrossRef]

21. Perrier, C.; Beroual, A.; Bessede, J.L. Improvement of power transformers by using mixtures of mineral oil with synthetic esters. IEEE Trans. Dielectr. Electr. Insul. 2006, 13, 556-564. [CrossRef]

22. Rao, U.M.; Sood, Y.R.; Jarial, R.K. Oxidation stability enhancement of a blend of mineral and synthetic ester oils. IEEE Electr. Insul. Mag. 2016, 32, 43-47. [CrossRef]

23. Yu, H.; Chen, R.; Hu, X.; Xu, X.; Xu, Y. Dielectric and physicochemical properties of mineral and vegetable oils mixtures. In Proceedings of the 19th IEEE International Conference on Dielectric Liquids (ICDL), Manchester, UK, 25-29 June 2017.

24. Beroual, A.; Khaled, U.; Noah, P.S.M.; Sitorus, H. Comparative study of breakdown voltage of mineral, synthetic and natural oils and based mineral oil mixtures under AC and DC voltages. Energies 2017, 10, 511. [CrossRef]

25. Hamadi, A.; Fofana, I.; Djillali, M. Stability of mineral oil and oil-ester mixtures under thermal aging and electrical discharges. IET Gener. Transm. Distrib. 2017, 11, 2384-2392. [CrossRef]

26. Dombek, G.; Gielniak, J. Fire safety and electrical properties of mixtures of synthetic ester/mineral oil and synthetic ester/natural ester. IEEE Trans. Dielectr. Electr. Insul. 2018, 25, 1846-1852. [CrossRef]

27. Nadolny, Z.; Dombek, G. Thermal properties of mixtures of mineral oil and natural ester in terms of their application in the transformer. In Proceedings of the International Conference on Energy, Environment and Material Systems (EEMS), Polanica-Zdrój, Poland, 13-15 September 2017; pp. 1-6.

28. Nadolny, Z.; Dombek, G.; Przybylek, P. Thermal properties of a mixture of mineral oil and synthetic ester in terms of its applications in the transformer. In Proceedings of the IEEE International Conference on Electrical Insulation and Dielectric Phenomena (CEIDP), Toronto, ON, Canada, 16-19 October 2016; pp. 857-860.

29. Gao, Y.; Li, F.; Lu, W.; Zhao, W. Effect of temperature on flow electrification under DC electrical field. J. Eng. 2019, 2019, 2893-2896. [CrossRef]

30. Zdanowski, M. Streaming electrification phenomenon of electrical insulating oils for power transformers. Energies 2020, 13, 3225. [CrossRef]

31. Zmarzły, D.; Frącz, P. Streaming electrification in the swinging plate system. IEEE Trans. Dielectr. Electr. Insul. 2017, 24, 3217-3225. [CrossRef]

32. Zmarzły, D.; Fracz, P. Dynamics of impulse response of streaming electrification current in swinging cylinder system insulation. IEEE Trans. Dielectr. Electr. Insul. 2018, 25, 713-720. [CrossRef]

33. Ren, S.; Liu, Q.; Zhong, L.; Yu, Q.; Xu, Y.; Cao, X.; Hanai, M.; Yamada, S.; Mori, S. Electrostatic charging tendency and correlation analysis of mineral insulation oils under thermal aging. IEEE Trans. Dielectr. Electr. Insul. 2011, 18, 499-505.

34. Leblanc, P.; Paillat, T.; Cabaleiro, J.M.; Touchard, G. Flow electrification investigation under the effect of the flow parameters. Int. J. Plasma Environ. Sci. Technol. 2018, 11, 156-160.

35. Zmarzły, D.; Kędzia, J. A noise analyzer for monitoring static electrification current. J. Electrost. 2005, 63, 409-422. [CrossRef]

36. Zdanowski, M.; Wolny, S.; Zmarzły, D.; Kędzia, J. The analysis and selection of the spinning disk system parameters for the measurement of static electrification of insulation oils. IEEE Trans. Dielectr. Electr. Insul. 2007, 14, 480-486. [CrossRef] 
37. Zdanowski, M. Electrostatic charging tendency analysis concerning retrofilling power transformers with Envirotemp FR3 natural ester. Energies 2020, 13, 4420. [CrossRef]

38. Zdanowski, M.; Maleska, M. Streaming electrification of insulating liquid mixtures. Arch. Electr. Eng. 2019, 68, 387-397.

39. Adamczewski, J. Ionization and Conductivity of Liquid Dielectric; Polish Scientific Publishers (PWN): Warsaw, Poland, 1965. (In Polish)

40. Zdanowski, M.; Ozon, T. Measuring system for a streaming electrification tests of insulating liquids. Poznan Univ. Technol. Acad. J. Electr. Eng. 2016, 86, 393-403. (In Polish)

41. Kedzia, J.; Willner, B. Electrification current in the spinning disc system. IEEE Trans. Dielectr. Electr. Insul. 1994, 1, 58-62. [CrossRef]

42. Rajab, A.; Gumilang, H.; Tsuchie, M.; Kozako, M.; Hikita, M.; Suzuki, T. Study on static electrification of the PFAE-mineral oil mixture. IOP Conf. Ser. Mater. Sci. Eng. 2019, 602, 012016. [CrossRef]

Publisher's Note: MDPI stays neutral with regard to jurisdictional claims in published maps and institutional affiliations.

(C) 2020 by the author. Licensee MDPI, Basel, Switzerland. This article is an open access article distributed under the terms and conditions of the Creative Commons Attribution (CC BY) license (http://creativecommons.org/licenses/by/4.0/). 